\title{
Irritable Bowel Syndrome, Gut Microbiota and Probiotics
}

\author{
Beom Jae Lee and Young-Tae Bak* \\ Department of Gastroenterology, Korea University Guro Hospital, Seoul, Korea
}

Irritable bowel syndrome (IBS) is a complex disorder characterized by abdominal symptoms including chronic abdominal pain or discomfort and altered bowel habits. The etiology of IBS is multifactorial, as abnormal gut motility, visceral hypersensitivity, disturbed neural function of the brain-gut axis and an abnormal autonomic nervous system are all implicated in disease progression. Based on recent experimental and clinical studies, it has been suggested that additional etiological factors including low-grade inflammation, altered gut microbiota and alteration in the gut immune system play important roles in the pathogenesis of IBS. Therefore, therapeutic restoration of altered intestinal microbiota may be an ideal treatment for IBS. Probiotics are live organisms that are believed to cause no harm and result in health benefits for the host. Clinical efficacy of probiotics has been shown in the treatment or prevention of some gastrointestinal inflammation-associated disorders including traveler's diarrhea, antibiotics-associated diarrhea, pouchitis of the restorative ileal pouch and necrotizing enterocolitis. The molecular mechanisms, as cause of IBS pathogenesis, affected by altered gut microbiota and gut inflammation-immunity are reviewed. The effect of probiotics on the gut inflammation-immune systems and the results from clinical trials of probiotics for the treatment of IBS are also summarized.

(J Neurogastroenterol Motil 2011;17:252-266)

Key Words

Immunity; Inflammation; Irritable bowel syndrome; Microbiota; Probiotics

\section{Introduction}

Irritable bowel syndrome (IBS) is a functional gastrointestinal (GI) disorder that is characterized by chronic abdominal discomfort or pain associated with bowel habit change such as diarrhea and constipation, without obvious organic abnormalities. IBS is not a serious illness, but it has a high prevalence with about $10 \%-15 \%$ of the adult population being afflicted with the disorder. The high prevalence of IBS is accompanied by large societal economic burdens and negative effects on the quality of life in af- fected patients. ${ }^{1,2}$

Although there have been many studies attempting to divulge the pathophysiology of IBS, the disease is still not clearly understood. Traditionally, an altered brain-gut axis has been accepted as a main pathogenetic mechanism of IBS, which is associated with a dysfunction of the GI autonomic nervous system. These alterations may lead to abnormal visceral hypersensitivity and aberrations of gut motility. ${ }^{3,4}$ Recently, additional potential mechanisms of IBS have emerged including alteration of gut microbiota and low-grade inflammation/immune activation. ${ }^{5-8}$ These factors might lead to abnormal motility and visceral hyper-

Received: May 112011 Revised: June 9, 2011 Accepted: June 11, 2011

(c) This is an Open Access article distributed under the terms of the Creative Commons Attribution Non-Commercial License (http://creativecommons. org/licenses/by-nc/3.0) which permits unrestricted non-commercial use, distribution, and reproduction in any medium, provided the original work is properly cited.

*Correspondence: Young-Tae Bak, MD

Department of Gastroenterology, Korea University Guro Hospital, 148 Gurodong-ro, Guro-gu, Seoul 152-703, Korea

Financial support: None.

Tel: +82-2-2626-1778, Fax: +82-505-115-1778, E-mail: drbakyt@korea.ac.kr

Conflicts of interest: None. 
sensitivity and contribute to the symptoms. ${ }^{4,7}$ Naïve gut microbiota plays important roles in the maintenance of gut homeostasis by direct bacteriocidal effects and the evolution of both innate and adaptive immune systems. ${ }^{10-14}$

Gut microbiota is thought to play important roles in the pathogenesis of IBS. This is evident from the fact that IBS occurs more frequently after intestinal infection or antibiotics treatment. Studies have shown that the alterations of the intestinal microbiota are observed in IBS patients. ${ }^{15-20}$ Considering the relationship between alteration of gut microbiota and inflammation of gut, manipulation of gut microbiota by probiotics appears to be an ideal treatment modality for IBS. However, the beneficial effects and efficacy of altering gut microbiota by probiotics to improve the symptoms of IBS have not been consistent in clinical trials and therefore it remains uncertain as an effective treatment.

This review summarizes the effects of altered gut microbiota on the pathogenesis of IBS, the action mechanisms of probiotics in gut inflammation/immune system and the results of clinical trials of probiotics in IBS.

\section{General Properties of Probiotics}

Probiotics are live microorganisms that have been considered to enhance health when administered in adequate amounts to the host. Probiotics have special characteristics that allow them to withstand the harsh conditions of the GI tract, including gastric acid and bile secretion, and can survive competition with other enteric microorganisms. ${ }^{17,21}$

Most probiotics were originally isolated from healthy humans and expected to be safe for humans. Clinical efficacy of probiotics has been shown in the treatment or prevention of some GI inflammation-associated disorders including traveler's diarrhea, antibiotics-associated diarrhea, necrotizing enterocolitis and pouchitis in a restorative ileal pouch. ${ }^{17}$ However, probiotics have not been shown as an effective treatment to maintain remission in patients with inflammatory bowel disease (IBD) and some probiotics (Lactobacillus species) caused adverse effects in some patients with Crohn's disease. ${ }^{22}$ Therefore, the administration of probiotics is not always indicated for the treatment of GI inflammation-associated disorders. ${ }^{17}$

Probiotics can stimulate the intestinal immune system. In recent studies, the immunostimulatory effects of some Lactobacillus species have been explored as live vectors for the delivery of other bioactive drugs. Lactobacillus gasseri and Lactobacillus johnsonii change the enteric mucosal cytokine profile by inducing the acti- vation of human dendritic cells (DCs). ${ }^{23}$ Probiotics are used in treating many diseases but studies on the molecular mechanism are still being conducted.

\section{Gut Microbiota and Intestinal Homeostasis}

Intestine is the primary interaction site between the host and microbiota. GI tract is colonized immediately after birth with up to $10^{12}$ organisms per gram of luminal contents in the colon. Some of these microorganisms are essential and helpful to normal physiology and maintain homeostasis as they have been shown to contribute profoundly to maintain the architecture and function of intestinal epithelial cells (IECs) including angiogenesis and development of IECs. ${ }^{24}$ Cooperation of the innate and adaptive immune systems is essential to protect the intestinal epithelium from inflammatory responses. ${ }^{10,25}$ Epithelial cells have a central role in the regulation of intestinal immunity providing a hospitable microenvironment for bacteria by maintaining stable temperature and supplying nutrients. Non-pathogenic bacteria also facilitate digestion, absorption and storage of nutrients, such as plant materials, that would otherwise be inaccessible to their mammalian hosts. ${ }^{26}$

The enteric immune system is composed of gut-associated lymphoid tissues and widespread lymphocytes in lamina propria. IECs, where there are receptors for microbial-associated molecular patterns including toll-like receptors (TLRs) similar to immune cells, play a central role in the regulation of intestinal immunity. Activation of these receptors stimulates the transcription of antimicrobial proteins, pro-inflammatory cytokines and chemokines via NF- $\mathrm{KB}$ pathway. This cascade pathway can be modulated by a soluble microbiota-derived factors including polysaccharide A from the human symbionts, such as Bacteroides fragilis. In addition, these soluble factors have been shown to promote the function of regulatory $\mathrm{T}$ cells (Treg) and the production of anti-microbacterial peptide, defensin 1, to maintain epithelial barrier function. ${ }^{14}$

Intestinal adaptive immunity is mediated by Peyer's patches or mesenteric lymph nodes. DCs may also play an important role in maintaining immune tolerance to non-pathogenic bacteria in the gut. DCs directly capture bacteria in the intestinal lumen without destruction of the tight junction or shift the bacteria through glycocalyx-free M cells that lay over Peyer's patches to mesenteric lymph node. ${ }^{21}$ Similar to this mechanism, DCs can harbor viable non-pathogenic bacteria that are retained and pre- 
vented from entering systemic immune compartment. ${ }^{27}$

It is through this interaction that DCs determine the state of gut immune system in terms of whether to induce or suppress immunity. Gut microbiota also have the ability to induce DC maturation and differentiation of naïve $\mathrm{T}$ cells into Th1, Th2, T17 or Treg. In the maintenance of gut homeostasis, non-pathogenic bacteria play an important role in the balance of adaptive immunity by the regulation of Treg. ${ }^{28}$ In pathogenic bacteria, IECs modulate the secretion of proinflammatory cytokines like IL-8, but probiotics do not induce this cytokines by the inhibition of $\mathrm{NF}-\kappa \mathrm{B}$ by suppressing the proteosomal degradations such as

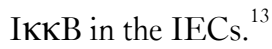

\section{Alterations in the Gut Microbiota in IBS}

Alteration of the gut microbiota has been suggested as a pathologic etiology in IBS. Change in gut flora may contribute to low-grade inflammatory responses. From clinical and epidemiologic studies, presence of small bowel bacterial overgrowth (SIBO) has been demonstrated in IBS patients. ${ }^{8,29}$ GI infection or antibiotics can perturb the composition of gut microbiota and this alteration has been associated with symptoms in IBS. ${ }^{19}$ The increased quantity of gut microbiota is a suggested evidence of the association of gut microbiota with IBS; however, its prevalence in IBS is not consistent. Studies on the relationships between the alterations in gut microbiota and GI disorders have limitations. The diversity of bacteria and the clinical symptoms of IBS are great and there are no exact molecular or organic markers to diagnose IBS. The assessment of the composition of gut microbiota is difficult and is confounded by large individual variations in microbiota. In addition, according to regions and countries, diverse eating culture (such as consumption of yogurts and fermented foods) and medicinal administration can change the composition of gut microbiota in individuals. ${ }^{15}$ Molecular techniques are widely used because of difficulties in culturing the gut microbiota, but these methods also have limitations. For example, polymerase chain reaction (PCR)-based techniques cannot distinguish between live and dead organisms. ${ }^{18}$ The exact role of this alteration is still controversial in the pathophysiology of IBS. This is due to the limited knowledge of gut microbiota due to the complexity, variability and instability of the indigenous gut microbiota of human subjects. ${ }^{17,18,30}$

\section{Post-infectious Irritable Bowel Syndrome}

It has been reported that the majority of patients recovered from acute infectious colitis due to Salmonella species, Campylobacter jejuni or Shigella species suffer from symptoms of IBS. ${ }^{31-34}$ Post-infectious IBS is known to develop in $6 \%-31 \%$ of acute infectious colitis and the risk factors include younger age, female gender, bloody stool and duration of diarrhea. ${ }^{34-36}$

There is a great deal of evidences for increased inflammation in patients with post-infectious IBS. Mild inflammation is seen in the colonic mucosa in patients with post-acute enteritis IBS. The number of chronic inflammatory cells in the colonic mucosa is increased in patients with IBS compared to those who do not develop IBS, with increases in the activation of $\mathrm{T}$ cells and inflammatory cytokine expression after 3 months of infection. ${ }^{37}$ IL-1 $\beta$ mRNA levels and the number of enterochromaffin cells are increased in the colorectal mucosa of patients with IBS compared to those without IBS. ${ }^{38,39}$ These studies support the role of low-grade inflammation in the mechanism of IBS.

\section{Alterations in Quantity of the Gut Microbiota}

Alteration of the indigenous gut microbiota in the pathogenesis of IBS is not only related to the types of microorganisms comprising the microbiota but also to their numbers. SIBO has been suggested to play a role in the generation of IBS symptoms including abdominal distention, bloating and flatulence. This is additional indirect evidence that alterations in the gut microbiota are pathogenic factors in IBS. SIBO might lead to increased gas fermentation, gas production and altered gut movement. ${ }^{40,41}$ However, the prevalence of SIBO in IBS is not consistent between clinical studies varying from $4 \%$ to $84 \%$. This inconsistency is due to the problems of hydrogen breath test that is commonly used as a diagnostic tool.

A recent study using the jejunal culture method showed that SIBO was observed in only $4 \%$ of patients with IBS and that the prevalence of SIBO was not significantly different in IBS patients compared to healthy control groups. ${ }^{8}$ This result did not show a strong relationship between IBS and SIBO, but slightly increased counts of small bowel bacteria were observed in IBS patients. Although the degree of bacterial overgrowth did not meet the criteria of SIBO, this result suggested that quantitative change of gut microbiota might be associated with pathogenesis of IBS.

Studies using antibiotics to target the intestinal microbiota to treat IBS have been performed. In some studies, short-term use 
of non-absorbable antibiotics including neomycin or rifaximin led to a significant improvement in IBS symptoms. ${ }^{42,43} \mathrm{~A}$ recent paper showed that a large double-blind, placebo-controlled trial in which subjects were administered $550 \mathrm{mg}$ dose of rifaximin 3 times daily for 3 weeks significantly relieved IBS symptoms of bloating and abdominal pain and improved stool consistency in patients with IBS without constipation. ${ }^{29}$ A possible explanation for this effect was suggested that the antibiotics reduced bacterial products such as short-chain fatty acids that cause IBS symptoms. ${ }^{44}$ Total concentration of short-chain fatty acids in jejunal secretions of SIBO patients is significantly higher than in healthy control. These organic acids may affect the bowel movement and clinical symptoms as a recent study showed that the concentrations of fecal acetic acid/propionic acid are correlated with GI symptoms, quality of life and negative emotion. In addition, antibiotic treatment may reduce the local mucosal engagement of bacteria to reduce the immune reaction between the host and the microbiota. ${ }^{45}$

\section{Alterations in Composition of the Gut Microbiota}

Alteration in composition of the intestinal microbiota is relevant to IBS and this information is an important prerequisite to define the exact role of gut microbiota in the pathogenesis of IBS. After birth, the gut microbiota begins colonization and stabilizes over the first 18 months of life. Although the characteristics of non-pathogenic bacteria remain to be clarified, the main compositional changes that affect gut-specific disorders are microbial stability and diversity. Many studies using various methodologies to define these changes have been conducted, including classic culture techniques and PCR-based molecular technology. Previous studies using classical culture methods have shown that there were decreased levels of coliforms, lactobacilli and Bifidobacterium species in IBS patients relative to healthy controls. ${ }^{46,47}$ A higher proportion of aerobic bacteria was present in the guts of IBS patients. ${ }^{47,48}$ However, these findings were not consistent and reproducible between studies. ${ }^{45,48}$ The fact that the complete composition of the gut microbiota remains to be elucidated and that all gut microbiota cannot be identified by classical culture methods may explain this inconsistency. ${ }^{18,47}$ In addition, the culture techniques differ across studies and many factors that affect the gut microbiota, including diet, antibiotic use and gut motility, are difficult to control. ${ }^{18}$

As new culture-independent molecular methods, including quantitative $\mathrm{PCR},{ }^{49}$ denaturing gradient gel electrophoresis $(\mathrm{DGGE})^{48}$ and fluorescent in situ hybridization, ${ }^{50,51}$ are now

Table 1. Summary of Studies on the Compositional Changes of Gut Microbiota in Patients With Irritable Bowel Syndrome

\begin{tabular}{|c|c|c|c|}
\hline Study & $\begin{array}{l}\text { Method of } \\
\text { confirmation }\end{array}$ & $\begin{array}{l}\text { No. of patients } \\
\text { (Diagnostic criteria) }\end{array}$ & Results \\
\hline Si et $\mathrm{al}^{47}$ & Culture & 25 (Rome II) & $\begin{array}{l}\text { Decreased amounts of Bifidobacteria species. } \\
\text { Increased amount of Enterobacteriaceae species in IBS patients. }\end{array}$ \\
\hline Tana et $\mathrm{al}^{45}$ & Culture & 26 (Rome II) & Increased Lactobacillus in IBS patients. \\
\hline Mättö et $\mathrm{al}^{48}$ & Culture/DGGE & 26 (Rome II) & $\begin{array}{l}\text { Increased number of aerobes in IBS patients. } \\
\text { Temporal instability in IBS patients revealed by DGGE. }\end{array}$ \\
\hline Malinen et $\mathrm{al}^{52}$ & qPCR & 27 (Rome II) & $\begin{array}{l}\text { Decreased amounts of Lactobacillus in IBS-D patients. } \\
\text { Increased amounts of Veillonella in IBS-C patients. }\end{array}$ \\
\hline Tana et $\mathrm{al}^{45}$ & qPCR & 26 (Rome II) & Increased Veillonella in IBS patients. \\
\hline Malinen et $\mathrm{al}^{49}$ & qPCR & 44 (Rome I) & $\begin{array}{l}\text { R. torques-like phylotype was associated with severity with bowel symptoms. C. cocleatum } \\
88 \% \text {, C. aerofaciens-like and C. eutactus } 97 \% \text { phylotypes were significantly reduced } \\
\text { among IBS patients with } R \text {. torques } 94 \% \text { detected. }\end{array}$ \\
\hline Noor et $\mathrm{al}^{53}$ & qPCR -DGGE & 11 (Rome II) & $\begin{array}{l}\text { Biodiversity of bacterial species were significantly lower in UC and IBS patients than } \\
\text { healthy controls. In UC and IBD patients, loss of Bacteriodes species. was observed. }\end{array}$ \\
\hline Swidsinski et al ${ }^{51}$ & FISH & 20 (Unidentified) & E. rectale-C. coccoides accounted for $>40 \%$ of the biofilm in IBS patients. \\
\hline Kassinen et $\mathrm{al}^{5}$ & $\begin{array}{l}\text { Nucleic acid } \\
\text { fractionation / } \\
\text { sequencing }\end{array}$ & 24 (Rome II) & $\begin{array}{l}\text { Significant differences in the levels of Coprococcus, Collinsella and Coprobacillus species } \\
\text { between IBS patients and healthy controls. }\end{array}$ \\
\hline
\end{tabular}

IBS, irritable bowel syndrome; DGGE, denaturing gradient gel electrophoresis; PCR, polymerase chain reaction; IBS-D, diarrhea-predominant IBS; IBS-C, constipation-predominant IBS; R. torques, Ruminococcus torques; C. cocleatum, Clostridium cocleatum; C. aerofaciens, Collinsella aerofaciens; C. eutactus, Coprococcus eutactus; $\mathrm{UC}$, ulcerative colitis; IBD, inflammatory bowel disease; E. rectale, Eubacterium rectale; C. coccoides, Clostridium coccoides. 
available, more detailed characterizations of the gut microbiota may be obtained from many studies. Extraction of microbial nucleic acid from fecal or mucosal biopsy samples can provide profiles of the resident microbes based on analyses of the small ribosomal subunit $16 \mathrm{~S}$ rRNA gene. The $16 \mathrm{~S}$ rRNA gene contains highly conserved regions of base sequences that are interspersed with hypervariable regions that reflect the evolutionary divergence of different bacterial species. Size of the $16 \mathrm{~S}$ rRNA gene (about 1,500 bp) is suitable for comparative sequence analysis and, through comparisons of sequences in genetic databases, isolates may be identified.

In the first study that addressed compositional differences in gut microbiota using quantitative PCR, significantly lower levels of lactobacilli were observed in diarrhea-predominant IBS patients than in constipation-predominant IBS. ${ }^{52}$ Counts for Veillonella species were significantly higher in the constipation-predominant IBS group than with healthy controls. Levels of Rhinobatos productus and Clostridium coccoides were significantly increased in all subtypes of IBS compared to healthy controls. ${ }^{52}$ Another study addressed microbiotic instability in fecal samples taken 6 months apart from IBS patients and healthy controls using fingerprint profiles generated by DGGE. ${ }^{48}$ A recent study using PCR-DGGE addressed the biodiversity of bacterial species in ulcerative colitis (UC) and IBS patients compared to healthy controls. A loss of Bacteroides species was observed in UC and IBS patients. ${ }^{53}$

Extensive 16S rRNA gene cloning and sequencing with $\% \mathrm{G}+\mathrm{C}$ profiling showed that there were significant differences in bacterial species, including Coprococcus, Collinsella and Coprobacillus species, between IBS patients and healthy controls. ${ }^{5}$ Another study comparing diarrhea-predominant IBS (IBS-D) and healthy controls with the same molecular methods showed that IBS-D patients were enriched in Proteobacteria and Firmicutes, but the number of Bacteroides and Acinetobacter were reduced compared to healthy controls. ${ }^{54}$ A study using fluorescent in situ hybridization showed that Bifidobacteria levels in fecal and duodenal brush samples of IBS patients were decreased compared to healthy subjects. ${ }^{50}$ These clinical results are summarized in Table 1 according to the methods employed.

Taken together, these studies demonstrated that there were significant quantitative and qualitative differences in gut microbiota between IBS patients and healthy controls. However, these data are few and contradictory. For example, a recent study by Tana et $\mathrm{al}^{45}$ yielded some similar results to that of previous studies in light of compositional microbiota differences between IBS and healthy controls; however, a contradictory result was found in that lactobacilli count increased in IBS patients than in controls using a culture-based method.

Therefore, further studies using novel molecular methods are required to clarify the bacterial species that are associated with the pathogenesis and symptoms of IBS patients.

\section{Immunity Activation in Irritable Bowel Syndrome Patients}

Compelling evidence for the role of inflammatory and immune stimuli in the development of IBS has accumulated from many studies. ${ }^{4}$ Visceral hypersensitivity and gut dysmotility associated with IBS symptoms may be secondary to other factors. In animal studies, immune activation impairs gut motility and increased activity in sensory pathways from the gut. ${ }^{17}$ Similar findings were also demonstrated in a human study in which the intestinal or systemic activation of innate and adaptive immunity was observed in a subpopulation of IBS patients. ${ }^{4}$ Mast cell concentrations in the colons of IBS patients were at significantly higher densities than mast cells in cecum of controls, but no significant increases were seen in other colorectal regions. ${ }^{55}$ Barbara et $\mathrm{al}^{56}$ showed that mast cell concentration was significantly elevated with increased concentrations in tryptase and histamine. In addition, the numbers of mast cells within $5 \mu \mathrm{m}$ of the nerve endings were increased in descending colonic mucosal biopsies from patients with IBS. The severity of abdominal pain was correlated to the number of mast cells near the colonic nerve endings.

TLRs are a family of pathogen-recognition receptors of the innate immune system. TLR4 is normally expressed throughout the intestine at low levels in both the epithelium and in lamina propria mononuclear cells, but the expression is increased in IBD, indicating that increased TLR4 expression may contribute to the initiation and maintenance of intestinal inflammation. ${ }^{57} \mathrm{In}$ a recent study, TLR4 and TLR5 were increased in the colonic mucosa of IBS patients compared to healthy controls. ${ }^{58}$ Increased levels of antibodies to bacterial flagellin and $\beta$-defensin-2 levels that have antimicrobial activity as a part of innate immunity were significantly elevated in patients with IBS compared with healthy controls. ${ }^{59-61}$ This result supports the association of innate immunity between gut microbiota and the host in IBS.

There are also several lines of evidence that IBS may be associated with activation of the adaptive immune response. $\mathrm{B}$ cells isolated from the blood of IBS patients were shown to be activated 64 and various $\mathrm{T}$ cells isolated from both blood and colonic 
biopsies showed increased activation levels in IBS patients than in healthy controls. ${ }^{4,9,62}$ Mucosal gene expression analysis showed that there are relatively stable alterations in colonic mucosal immunity in IBS with increased expression involved a yet uncharacterized gene like DKFZP564O0823. ${ }^{63}$

\section{Action Mechanisms of Probiotics in Irritable Bowel Syndrome Treatment}

There have been numerous studies and a number of reviews to demonstrate the mechanisms by which probiotics exert their beneficial effects on the host. These studies were mainly performed in the IBD or animal colitis models. Suggested mechanisms of probiotics are as follows: the influence of intestinal luminal environment, the maintenance of epithelial and mucosal barrier function and the modulation of mucosal or systemic immune system including both innate and adaptive immune systems. ${ }^{11,12,64}$ Although it might be rather too early to make a conclusion that whether these mechanisms could be adapted to the pathogenesis of IBS, there is a growing body of evidence that supports the association of gut inflammation/immunity and IBS and define the roles of probiotics in the pathogenesis of IBS.

\section{Altered Intestinal Luminal Environment}

From the fecal analysis, alteration of gut microbiota is related to the pathogenesis of IBS. ${ }^{5,52}$ One of the possible and expected beneficial effects of probiotics is that supplement with probiotics could alter the intestinal luminal environment or microbiota composition in IBS patients. Probiotics can preserve intestinal homeostasis and restore the dysbiosis by the maintenance of luminal acidity, inhibition of bacterial adherence and producing antibacterial substance such as bacterocin and defensin. Previous study has shown that 4 weeks of treatment with Lactobacillus plantarum improved symptoms such as pain and flatulence in IBS patients and these effects continued for 1 year. L. plantarum was found in the feces $(84 \%)$ and rectal mucosa (34\%) only in the treated group. ${ }^{65}$ This result showed that probiotics could alter the host gut microbiota composition with improvement of IBS symptoms. With transient exposure to host, probiotics could exert their beneficial effects. It was suggested that colonization of the gut may not be essential for the function of probiotics, depending on the strain and biological effects of interest. ${ }^{21}$

\section{Intestinal Mucosal Barrier Function}

Intestinal barrier function is maintained by many factors in- cluding mucous layer, secretary IgA, chloride and water secretion and the epithelial junctional adhesion complex. Disruption of the barrier function can lead to the loss of immune tolerance of microbiota in the gut and aberrant immune response. This phenomenon is observed in inflammation-associated bowel disorders including IBD, enteric infection and celiac disease. ${ }^{11,12}$

There have been numerous experimental studies about the roles of probiotics to maintain this barrier function. In mice chronic colitis including IL-10 $0^{-/}$and methotrexane-induced models, Lactobacilli species improved barrier function. However, the exact mechanisms by which the species is effective for improvement of barrier function are still not evident. There is a growing body of evidence that disturbances of this barrier may play a contributory role in the development of IBS symptoms and lead to gut dysfunction. Indeed, elevated intestinal permeability has been documented in $12 \%-50 \%$ of IBS patients, depending on the infective nature of IBS, inclusion of patients with adverse reaction to food or various IBS criteria. ${ }^{66,67}$ Permeability of colonic mucosa was significantly higher in patients with IBS compared to healthy subjects. These changes were associated with significantly low expression of epithelial tight junction protein, ZO-1, mRNA in the colonic tissues of IBS. ${ }^{68}$

Another recent study showed that small bowel and colonic mucosal permeability was significantly decreased in patients with IBS-D compared with that of healthy controls using a triple sugar test (10 g lactulose, $5 \mathrm{~g}$ mannitol and $5 \mathrm{~g}$ sucralose) with the decreased levels of both ZO-1 and occludin. After taking probiotic-fermented milk (Streptococcus thermophilus, Lactobacillus bulagaris, Lactobacillus acidophilus and Bifidobacterium longum), the proportion of patients with increased small bowel permeability was decreased significantly and global IBS score improved compared with the baseline level, while there was no significant change of the level of colonic permeability after treatment of probiotics. $^{69}$

\section{Modulation of Immunity}

The necessity to regulate immune responses to commensal bacteria is exemplified by evidence that dysregulation of the balance between tolerance and immunity can contribute to the pathogenesis of numerous inflammatory conditions, including food allergies, IBD and intestinal cancer. ${ }^{70}$ If the delicate balance between the host immune system and the microbiota is altered, the host can disrupt the beneficial functions of the microbiota. This is seen in cases of intestinal inflammation such as Crohn's disease and UC. ${ }^{71}$ Probiotics have various effects on the immune 
system; stimulation or suppression of innate or adaptive immunity. Whether probiotics stimulate or suppress the inflammation or immunity might depend on the species or strain of the microorganisms. Administration of VSL\#3 in SAMP1/YitFC mice prevented the onset of gut inflammation through stimulation of epithelial innate response (epithelial TNF- $\alpha$ and NF- $\mathrm{NB}$ ) and restored the impaired innate immunity system to maintain intestinal epithelial barrier function and thereby prevent the onset of the gut inflammation. ${ }^{72}$ Anti-inflammatory effect of same probiotics could be different. Lactobacillus reuteri showed increased proinflammatory cytokine (IL-8) in vitro, but the same strain showed a strong in vivo anti-inflammatory effects. ${ }^{73}$ So, to clarify the exact anti-inflammatory mechanism of probiotics, the interaction between intestinal epithelial cells and immune mediated cells need to be further evaluated. There is growing evidence that defines the low grade inflammation-immune activation as a pathogenesis of IBS. The ratio of IL-10/IL-12 cytokines from peripheral monocytes, an indicator of a pro-inflammatory state, is decreased in IBS patients comparing to healthy control. ${ }^{74}$ Basal or lipopolysaccharide-stimulated levels of TNF- $\alpha$, IL-1 $\beta$ and IL-6 from peripheral monocytes were higher in IBS-D patients than that of healthy controls. However, in constipation-predominant IBS patients, only increased level of IL- $1 \beta$ was observed. ${ }^{75}$ Therefore, pattern of cytokine expression could explain the symptom manifestations whether diarrhea or constipation is predominant. During the last decades, several studies have implicated that activated adaptive immune response may be associated with the pathogenesis of IBS. Infiltration of both CD3+ and CD25 + T lymphocytes was increased in the epithelial cells of colon of IBS patients without microscopic inflammation. Recently, Ohman et $\mathrm{al}^{76}$ have demonstrated that both peripheral $\mathrm{T}$ cells and $\mathrm{B}$ cells were activated in IBS patients. Peripheral blood B cells of IBS patients have an increased activation with increased CD80 and CD86 expressions. Also, the frequency of co-expressing integrin $\beta 7+$ (gut homing receptor) $\mathrm{CD} 80+$ and integrin $\beta 7^{+} \mathrm{CD} 86^{+} \mathrm{B}$ cells were increased in blood of IBS patients than controls. Furthermore, integrin $\beta 7^{-} \mathrm{CD} 86^{+}$cell increased in IBS patients, suggesting that IBS patients also have an increased B cell activation in extra-intestinal lymph nodes. ${ }^{76}$ Same group has shown that IBS patients have an increased frequency of activated $\mathrm{T}$ cells. While there was no difference in the total number of CD4+ helper $\mathrm{T}$ cells and $\mathrm{CD} 8+$ cytotoxic $\mathrm{T}$ cells between IBS and healthy controls, the frequency of isolated CD4+ and CD8 + T cells expressing CD69, a marker for T cell activation were increased in IBS patients than in healthy controls.
$\mathrm{T}$ cells co-expressing HLA-DR and integrin $\beta 7$ were also increased in IBS patients. ${ }^{62}$ Many experimental studies have implicated that probiotics have an anti-inflammatory and modulation of gut immunity but there is lack of evidence that probiotics have an effect on inflammatory mileu and immunologic reaction in patients with IBS. O'Mahony et $\mathrm{al}^{74}$ evaluated the anti-inflammatory properties of Bifidobacterium infantis in humans. The levels of cytokines IL-10 and IL-12 were assessed both at baseline and after treatment with either B. infantis or Lactobacillus salivarius. After treatment with B. infantis, these cytokine levels returned to levels consistent with those observed in controls and the IL-10/IL-12 ratio became normalized. These findings support a theory that the mechanism for symptomatic improvement in patients receiving $B$. infantis appears to be a down-regulation of proinflammatory state. ${ }^{74}$ To define the exact roles of probiotics in IBS, further trial should be designed to investigate the immunologic reaction of probiotics in humans and the correlation between symptoms of IBS and immune cell activities.

\section{Neurosensory Enteric Nervous System}

Altered visceral perception and gut dysmotility are important contributors to symptoms of IBS. Visceral hypersensitivity is the main mechanism inducing abdominal pain in IBS patients, who show a lower threshold for discomfort compared with healthy controls. It has been known that the interaction between commensal microbiota and host has an important role in the modulation of inflammatory hypernociception. ${ }^{77}$ In experimental studies, some probiotics have the potential to modulate this visceral hypersensation. L. acidophilus can blunt visceral pain responses by increasing expression of enterocyte opioid and cannabinoid receptors and by inhibiting sodium channels. ${ }^{78,79}$ B. infantis 35624 significantly reduced the colorectal distension-induced visceral pain behaviors in experimental rats. ${ }^{80}$ Lactobacillus paracasei in spent culture medium prevented the antibiotics-induced visceral hypersensitivity and decreased both myeloperoxidase and substance $\mathrm{P}$ activities in mice colon. ${ }^{81}$ Administration of $L$. reuteri reduced size of the myenteric AH cell slow afterhyperpolarization by decreasing calcium channel-dependent potassium channel ( $\mathrm{IK}_{\mathrm{Ca}}$ ) opening. ${ }^{82}$

Probiotics can moderate gut motility by a direct action on enteric nervous system or via epithelial cells. It has been known that probiotics could interact with the enteric nervous system to attenuated diarrhea from infectious or secretory diarrhea. In experimental studies, Lactobacillus inhibited post-infective intestinal hypercontractility through an unidentified, heat-labile fermenta- 


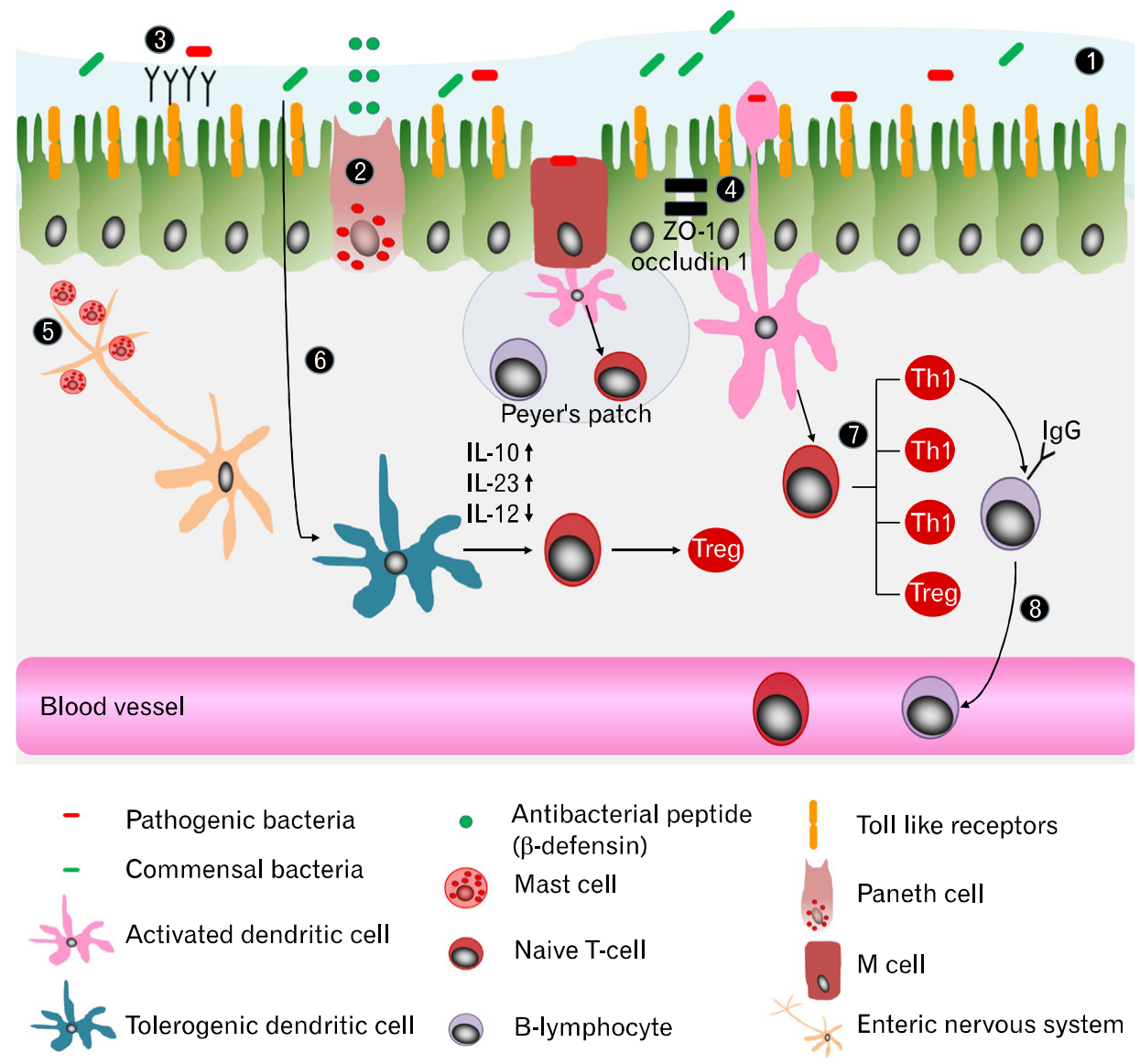

Figure. Mechanisms for preserving mucosal barrier function. To protect intestinal epithelium from noxious inflammatory process, there are several mechanisms to preserve mucosal barrier function; (1) mucous layer, (2) production of antimicrobial peptides by paneth cell, (3) secretary IgA and (4) epithelial-cell tight junction complex (eg, ZO-1 and occludin 1). Specialized intestinal epithelial cells which overlie Peyer's patches facilitate luminal sampling and transport of microbiota. (5) Mucosal mast cells are increased in small and large bowel. Their localization, number and mediators are correlated with generation of irritable bowel syndrome (IBS) symptom. Increased mast cells close to ending of nerve fiber are associated with perception of pain in IBS patients. (6) Dendritic cells (DC) interact with gut microbiota and other stimuli to determine if immune response or tolerance will be induced. Microbial factors interact with different DC cell surface pattern recognition receptors to determine DC maturation that produce IL- $1 \beta$, IL-6 and IL-23. Activated DCs subsequently regulate the differentiation of naïve T cells into Th1, Th2, Th17 or Treg. In IBS patients infiltration of CD3+ and CD25 $+\mathrm{T}$ cells are increased in colonic mucosa and blood $\mathrm{T}$ cell are activated with expression CD 69 and HLA-DR/integrin $\beta 7$. The proinflammatory cytokines from Th1 induce switching to IgG producing cell. Frequency of (7) IgG $+\mathrm{B}$ cells are increased in the blood of IBS patients with increased expression of $\mathrm{CD} 80 / 86$.

tion-product and by blocking calcium-dependent potassium channels. $^{83,84}$

Supernatant of Escherichia coli Nissle 1917 enhanced human colonic motility in vitro and acute exposure of colonic mucosa to Lactobacillus rhamnosus GG significantly reduced the acetylcholine-stimulated human colonic contractions in a dose- and time-dependent manners. ${ }^{85,86}$ Administration of L. reuteri altered the motility of ex vivo colonic segment of rat; it decreased the amplitudes of contractions and increased intraluminal fluid filling pressure thresholds for evoking pressure pulses. ${ }^{79}$ This result was similar to the effect of $\mathrm{IK}_{\mathrm{Ca}}$ channel blocking by TRAM-34 on rat colonic motility and myenteric neurons.

Taken together, association of the alteration of gut microbiota, inflammation-immune reaction and IBS have been demonstrated from many experimental and clinical studies. Manipulation of the intestinal microbiota by probiotics looks like promising treatment modality. However, further studies are needed to identify how the microbiota and probiotics interact with the host from gut microbiota to systemic gut sensory-motor dysfunctions (Figure). 
Table 2. Summary of Randomized Controlled Trials of Probiotics in Patients With Irritable Bowel Syndrome

\begin{tabular}{|c|c|c|c|c|c|c|}
\hline Study & Probiotics & & $\begin{array}{c}\text { Dosage } \\
(\mathrm{CFU} / \mathrm{mL})\end{array}$ & $\begin{array}{l}\text { No. of patients } \\
\text { (Diagnostic } \\
\text { criteria) }\end{array}$ & $\begin{array}{l}\text { Duration } \\
\text { (wk) }\end{array}$ & Results \\
\hline & Single & & & & & \\
\hline Sinn et $\mathrm{al}^{108}$ & $\begin{array}{l}\text { Lactobacillus } \\
\text { species }\end{array}$ & $\begin{array}{l}\text { L. acidophilus SDC 2012, } \\
2013\end{array}$ & $2 \times 10^{9}$ & $\begin{array}{c}40 \\
\text { (Rome III) }\end{array}$ & 4 & $\begin{array}{l}\text { Significant reduction in abdominal pain } \\
\text { and discomfort }(P=0.011)\end{array}$ \\
\hline Sen et $\mathrm{al}^{102}$ & & L. plantarum 299V & $5 \times 10^{7}$ & $\begin{array}{c}12 \\
\text { (Rome II) }\end{array}$ & 4 & $\begin{array}{l}\text { Failed to improve IBS symptoms and to } \\
\text { alter colonic fermentation }\end{array}$ \\
\hline Niedzielin et al ${ }^{101}$ & & & $5 \times 10^{7}$ & $\begin{array}{c}40 \\
(\text { not } \\
\text { characterized) }\end{array}$ & 4 & $\begin{array}{l}\text { IBS symptom improvement (pain, } \\
\text { constipation, diarrhea and flatulence): } \\
95 \% \text { vs } 15 \%(P<0.001)\end{array}$ \\
\hline Nobaek et al ${ }^{65}$ & & & $5 \times 10^{7}$ & $\begin{array}{c}60 \\
\text { (Rome II) }\end{array}$ & 4 & $\begin{array}{l}\text { Significant improvement in flatulence } \\
\text { over placebo: } 44 \% \text { vs } 18 \%(P<0.05)\end{array}$ \\
\hline Bausserman et $\mathrm{al}^{100}$ & & L. rhamnosus GG & $1 \times 10^{10}$ & $\begin{array}{l}50 \text { (children) } \\
\text { (Rome II) }\end{array}$ & 6 & $\begin{array}{l}\text { Not superior to placebo in relieving } \\
\text { abdominal pain }\end{array}$ \\
\hline Gawronska et al $^{109}$ & & & $3 \times 10^{9}$ & $\begin{array}{l}37 \text { (children) } \\
\text { (Rome II) }\end{array}$ & 4 & $\begin{array}{l}\text { Treatment success (resolution of pain and } \\
\text { relaxed face): } 33 \% \text { vs } 5.1 \%(P=0.04) \\
\text { reduced frequency of pain }(P=0.02)\end{array}$ \\
\hline O'Mahony et $\mathrm{al}^{74}$ & & L. salivarius UCC 4331 & $1 \times 10^{10}$ & $\begin{array}{c}67 \\
\text { (Rome II) }\end{array}$ & 8 & $\begin{array}{l}\text { No significant improvement in compo- } \\
\text { site and individual score (abdominal } \\
\text { pain/discomfort, bloating/distention and } \\
\text { bowel movement difficulty) over place- } \\
\text { bo }\end{array}$ \\
\hline Niv et al $^{99}$ & & L. reuteri ATCC 55730 & $1 \times 10^{8}$ & $\begin{array}{c}54 \\
\text { (Rome II) }\end{array}$ & 6 months & $\begin{array}{l}\text { No significant improvement of IBS } \\
\text { symptoms over placebo }\end{array}$ \\
\hline 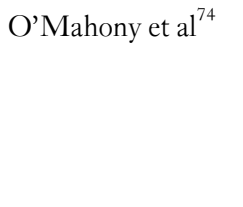 & $\begin{array}{l}\text { Bifidobacteria } \\
\text { species }\end{array}$ & B. infantis 356724 & $1 \times 10^{10}$ & $\begin{array}{c}67 \\
\text { (Rome II) }\end{array}$ & 8 & $\begin{array}{l}\text { Significant improvement in composite } \\
\text { and individual scores (abdominal pain/ } \\
\text { discomfort, bloating/distention and bo- } \\
\text { wel movement difficulty) over placebo } \\
(P<0.05)\end{array}$ \\
\hline Whorwell et $\mathrm{al}^{95}$ & & & $1 \times 10^{8}$ & $\begin{array}{l}362 \text { (women) } \\
\text { (Rome II) }\end{array}$ & 4 & $\begin{array}{l}\text { Improvement in global symptom } \\
\text { assessment exceed placebo by more than } \\
20 \%(P<0.01)\end{array}$ \\
\hline 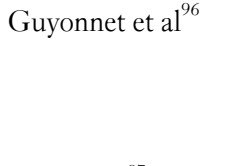 & & B. animalis DN $173010^{\mathrm{a}}$ & $1.2 \times 10^{10}$ & $\begin{array}{c}274 \\
\text { (Rome II, } \\
\text { IBS-C) }\end{array}$ & 6 & $\begin{array}{l}\text { Although health-related quality of life } \\
\text { and digestive symptom was improved } \\
\text { over baseline, there was no significant } \\
\text { difference comparing to placebo. }\end{array}$ \\
\hline 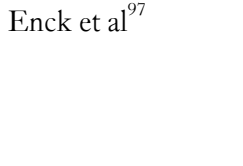 & $\begin{array}{l}\text { Escherichia } \\
\text { species }\end{array}$ & E. coli DSM 17252 & Symbioflor $2^{b}$ & $\begin{array}{l}298 \\
\text { (criteria of } \\
1 \text { care } \\
\text { physicians) }\end{array}$ & 8 & $\begin{array}{l}\text { Improvement of global symptom score } \\
\text { and abdominal pain score comparing to } \\
\text { placebo: } 18.4 \% \text { vs } 4.7 \%, 18.9 \% \text { vs } \\
6.67 \%(P<0.001)\end{array}$ \\
\hline Kim et $\mathrm{al}^{105}$ & Mixed & VSL \# 3 & $4.5 \times 10^{11}$ & $\begin{array}{l}25^{\mathrm{a}} \\
\text { (Rome II, } \\
\text { IBS-D) }\end{array}$ & 8 & $\begin{array}{l}\text { Reduction in abdominal bloating }(P= \\
0.046) \text {, no difference in other symp- } \\
\text { toms }\end{array}$ \\
\hline Kim et $\mathrm{al}^{106}$ & & & $4.5 \times 10^{11}$ & $\begin{array}{c}48 \\
\text { (Rome II) }\end{array}$ & 4 & $\begin{array}{l}\text { Reduction in flatulence }(P=0.011) \\
\text { retard colonic transit }(P=0.05) \text {, failed } \\
\text { to improve IBS symptoms of bloating, } \\
\text { pain and urgency }\end{array}$ \\
\hline
\end{tabular}


Table 2. Continued

\begin{tabular}{|c|c|c|c|c|c|c|}
\hline Study & Probiotics & & $\begin{array}{c}\text { Dosage } \\
(\mathrm{CFU} / \mathrm{mL})\end{array}$ & $\begin{array}{l}\text { No. of patients } \\
\text { (Diagnostic } \\
\text { criteria) }\end{array}$ & $\begin{array}{l}\text { Duration } \\
\text { (wk) }\end{array}$ & Results \\
\hline Kajander et $\mathrm{al}^{104}$ & & $\begin{array}{l}\text { L. rhamnosus GG, } \\
\text { L. rhamnosus LC705, } \\
\text { B. breve Bb99 and } \\
\text { P. freudenreichii spp. } \\
\text { shermanii JS }\end{array}$ & $8-9 \times 10^{9}$ & $\begin{array}{c}86 \\
\text { (Rome II) }\end{array}$ & 20 & $\begin{array}{l}\text { Significant reduction in IBS symptoms } \\
\text { (pain, distension, flatulence and rumbl- } \\
\text { ing) }(P=0.008)\end{array}$ \\
\hline Kajander et $\mathrm{al}^{103}$ & & & $8-9 \times 10^{9}$ & $\begin{array}{c}103 \\
\text { (Rome I or II) }\end{array}$ & 26 & $\begin{array}{l}\text { Significant reduction in total symptom } \\
\text { score (abdominal pain, distension, } \\
\text { flatulence and borborygmi) }(P<0.015)\end{array}$ \\
\hline Williams et $\mathrm{al}^{110}$ & & $\begin{array}{l}\text { L. acidophilus (NCIMB } \\
30157 \text { and NCIMB } \\
30156 \text { ), B. lactis } \\
\text { (NCIMB 30172) and } \\
\text { B. bifidum (NCIMB } \\
\text { 30153) }\end{array}$ & $2.5 \times 10^{10}$ & $\begin{array}{c}52 \\
\text { (Rome II) }\end{array}$ & 8 & $\begin{array}{l}\text { Significant reduction in symptom seve- } \\
\text { rity score and number of days with pain } \\
\text { and improvement of satisfaction of } \\
\text { bowel habit, quality of life over placebo } \\
(P<0.05)\end{array}$ \\
\hline Tsuchiya et al $^{111}$ & & $\begin{array}{l}\text { L. helviticus, } \\
\text { L. acidophilus, } \\
\text { Bifidobacterium }\end{array}$ & $10 \mathrm{~mL}$ t.i.d. ${ }^{\mathrm{c}}$ & $\begin{array}{c}68 \\
\text { (Rome II) }\end{array}$ & 12 & $\begin{array}{l}\text { Symptom improvement of IBS: } 80 \% \text { vs } \\
10 \%(P<0.01)\end{array}$ \\
\hline $\begin{array}{l}\text { Drouault-Holowacz } \\
\text { et }^{112}\end{array}$ & & $\begin{array}{l}\text { B. longum LA } 101 \text { (29\%), } \\
\text { L. acidophilus LA } 102 \\
(29 \%) \text {, L. lactis LA } 103 \\
(29 \%) \text { and } \\
\text { S. thermophilus LA } 104 \\
(13 \%)\end{array}$ & $1 \times 10^{9}$ & $\begin{array}{c}100 \\
(\text { Rome II) }\end{array}$ & 4 & $\begin{array}{l}\text { No significant improvement of IBS } \\
\text { symptom over placebo }\end{array}$ \\
\hline Hong et $\mathrm{al}^{107}$ & & $\begin{array}{l}\text { B. bifidum } \mathrm{BGN} 4 \text {, } \\
\text { B. lactis AD011, } \\
\text { L. acidophilus } \mathrm{AD} 031 \\
\text { and L. casei } \mathrm{IBS} 041\end{array}$ & $2 \times 10^{9}$ & $\begin{array}{c}70 \\
\text { (Rome III) }\end{array}$ & 8 & $\begin{array}{l}\text { Significant reduction in pain over pla- } \\
\text { cebo }(P=0.045)\end{array}$ \\
\hline
\end{tabular}

${ }^{a}$ Fermented milk containing B. animalis DN-173010 together with the 2 classical yoghurt starters (S. thermophilus and L. bulgaricus, $\left.1.2 \times 10^{9} \mathrm{CFU} / \mathrm{pot}\right){ }^{\mathrm{b}} \mathrm{Symbioflor}-2$ is an E. coli 17252 preparation, $1 \mathrm{~mL}$ containing 1.5 to $4.5 \times 10^{7} \mathrm{CFU}$; Composition for $100 \mathrm{~mL}$ : L. acidophilus $1.25 \times 10^{6}$, L. helveticus $1.3 \times 10^{9}$ and Bifidobacterium $4.95 \times 10^{9}$.

IBS, irritable bowel syndrome; IBS-C, constipation-predominant IBS; IBS-D, diarrhea-predominant IBS.

\section{Clinical Trials of Probiotics in Irritable Bowel Syndrome}

There have been many clinical studies investigating therapeutic benefits of probiotics in patients with IBS. However, due to heterogeneity in species or strains of the microorganisms, treatment duration and characteristics of the enrolled patients, earlier results were not consistent. ${ }^{18,87,88}$ Recently, several systematic reviews and meta-analyses have provided reliable data regarding the use of probiotics for the treatment of IBS. ${ }^{88-92}$ Table 2 summarizes the clinical results of controlled studies classified by the probiotic species used. According to recently published meta-an- alyses of probiotics in IBS, there is a general agreement that probiotics decrease global IBS symptoms. ${ }^{89-91}$ However, these meta-analyses and systematic reviews also had limitations due to diversity and heterogeneity of the species used, enrolled patients and intervention periods.

Most studies suggested that Bifidobacterium, possibly Lactobacillus species and E. coli DSM 17252 had benefits in IBS treatment. $^{87,88,92-94}$ In a trial with 75 patients who satisfied the Rome II criteria of IBS, B. infantis 35624 reduced pain, bloating, distension and defecatory symptoms in patients; it also reduced the composite symptom score. ${ }^{74}$ Another large multicenter trial in 362 women with all subtypes of IBS, randomized to four groups taking dose of $10^{6}, 10^{8}, 10^{10} \mathrm{CFU}$ or placebo showed that treat- 
ment with $B$. infantis for 4 weeks was significantly superior to placebo in improving the composite symptom score, especially in patients with IBS-D. ${ }^{95}$

A French group designed a large multicenter trial of fermented milk containing Bifidobacterium animalis DN 173010 and showed beneficial effect on bloating in controls and on stool frequency in patients with less than 3 bowel movements per week. However, due to a considerable placebo effect, the health-related quality of life discomfort score and the primary endpoint were not significantly different between the test product and placebo. ${ }^{96}$

A primary care-based placebo-controlled E. coli DSM 17252 trial was conducted in 298 patients with IBS. Treatment of IBS by Symbioflor-2 (E. coli DSM 17252 preparation, $1 \mathrm{~mL}$ containing 1.5 to $4.5 \times 10^{7} \mathrm{CFU}$ ) for 8 weeks was superior to placebo in achieving complete resolution $(18.2 \%$ vs $4.7 \%, P<0.001)$ and in reducing abdominal pain $(18.9 \%$ vs $6.7 \%, P=0.002){ }^{97}$

There have been several trials with Lactobacillus species ${ }^{65,98-102}$ A small single center study of 40 patients with IBS who met the Rome III criteria showed that treatment of $L$. acidophilus SDC 2012 and 2013 for 4 weeks had beneficial effect over placebo in ameliorating abdominal pain. ${ }^{98}$ Another small-sized study of 55 patients with IBS using a treatment with $L$. reuteri ATCC 5570 for 6 months showed improvement in the global symptom score compared to baseline, but failed to demonstrate superiority over placebo due to a high placebo effect. ${ }^{99}$ Another strain, L. plantarum $299 \mathrm{v}$ showed beneficial effect in 2 interventions. ${ }^{65,101}$ Treatment of L. plantarum 299v for 4 weeks in 60 patient with IBS significantly and rapidly reduced flatulence compared with placebo treatment, but there was no difference in the reduction of abdominal pain and bloating between the 2 groups. ${ }^{65}$ Another similar study in 40 patients with IBS significantly ameliorated abdominal pain and improved all IBS symptoms compared to placebo. ${ }^{101}$ However, one trial failed to yield any effect compared with the controls. ${ }^{102}$

Use of multispecies probiotics has shown favorable effects in controlling symptoms of IBS. Two trials with combination of multi-species probiotics (L. rhamnosus GG, L. rhamnosus LC705, Bifidobacterium breve and Propionibectaerium freudenreichii species shermanii JS) for longer periods of 5 and 6 months have shown that total symptom scores (sum of primary symptom scores for abdominal pain, distension, flatulence and borborygmi) became significantly lower in the probiotics group. ${ }^{103,104}$ In a trial on 25 IBS-D patients treated with VSL\#3 probiotics or placebo for 8 weeks, abdominal bloating was slightly reduced in the probiotics group, but the difference between the active and placebo groups was not significant. Effects on the mean GI transit measurements, bowel function scores or global symptom reliefs were not different between the 2 groups. ${ }^{105}$ In a second trial targeting on IBS patient with bloating (48 patients), probiotics significantly reduced flatulence compared with the placebo group and retarded colonic transit. ${ }^{106}$ However, bloating and abdominal pain scores were not different between the 2 groups. In a recent Korean study for IBS patients who met Rome III criteria, treatment with multispecies probiotics (Bifidobacterium bifidum BGN4, Bifidobacterium lactis AD011, L. acidophilus AD031 and Lactobacillus casei IBS041) significantly improved abdominal pain and defecation difficulty in IBS patients compared to healthy controls. ${ }^{107}$ However, further well-designed, large-scale studies are needed before recommending the use of multispecies formulations for the treatment of IBS.

\section{Conclusions and Future Directions}

In recent years, numerous studies have been conducted to understand the pathogenesis and treatment of IBS. However, IBS remains one of the most difficult GI disorders to manage regardless of its benign nature. Recommending probiotics has long been an alternative to the conventional medicine for the treatment of many diseases and is an attractive treatment modality for IBS considering its low costs and favorable safety profiles. In the context of dysbiosis as the pathogenesis of IBS, probiotic treatment seems reasonable and possibly ideal as it restores the intestinal microbiota. Many studies have indicated that probiotics might play important roles in maintaining gut homeostasis by the modulation of immunity and increasing epithelial barrier function. Clinical studies and systemic meta-analyses have shown that some strains of probiotics have beneficial effects in selected patients.

However, a number of controversial issues regarding the roles of probiotics in pathogenesis and treatment of IBS remain to be clarified. To be accepted as a definite treatment option, it should be clarified that in which subset of patients probiotics are effective, which species are effective, which is preferred in terms of a single or mixed species and which dosage and duration of treatment are optimum. To solve this problem, future well-designed, large-scale clinical trials should be performed using proper diagnostic criteria. Researches to widen and deepen our understanding of the effects of probiotics on a basic physiological level are also required. 


\section{References}

1. Longstreth GF, Thompson WG, Chey WD, Houghton LA, Mearin F, Spiller RC. Functional bowel disorders. Gastroenterology 2006;130:1480-1491.

2. Drossman DA, Camilleri M, Mayer EA, Whitehead WE. AGA technical review on irritable bowel syndrome. Gastroenterology 2002;123:2108-2131.

3. Ohman L, Simrén M. New insights into the pathogenesis and pathophysiology of irritable bowel syndrome. Dig Liver Dis 2007;39:201215 .

4. Ohman L, Simrén M. Pathogenesis of IBS: role of inflammation, immunity and neuroimmune interactions. Nat Rev Gastroenterol Hepatol 2010;7:163-173.

5. Kassinen A, Krogius-Kurikka L, Mäkivuokko H, et al. The fecal microbiota of irritable bowel syndrome patients differs significantly from that of healthy subjects. Gastroenterology 2007;133:24-33.

6. Ghoshal UC, Kumar S, Mehrotra M, Lakshmi C, Misra A. Frequency of small intestinal bacterial overgrowth in patients with irritable bowel syndrome and chronic non-specific diarrhea. J Neurogastroenterol Motil 2010;16:40-46.

7. Karantanos T, Markoutsaki T, Gazouli M, Anagnou NP, Karamanolis DG. Current insights in to the pathophysiology of irritable bowel syndrome. Gut Pathog 2010;2:3.

8. Posserud I, Stotzer PO, Björnsson ES, Abrahamsson H, Simrén M. Small intestinal bacterial overgrowth in patients with irritable bowel syndrome. Gut 2007;56:802-808.

9. Chadwick VS, Chen W, Shu D, et al. Activation of the mucosal immune system in irritable bowel syndrome. Gastroenterology 2002; 122:1778-1783.

10. Lee YK, Mazmanian SK. Has the microbiota played a critical role in the evolution of the adaptive immune system? Science 2010;330: 1768-1773.

11. Ohland CL, Macnaughton WK. Probiotic bacteria and intestinal epithelial barrier function. Am J Physiol Gastrointest Liver Physiol 2010;298:G807-G819.

12. Ng SC, Hart AL, Kamm MA, Stagg AJ, Knight SC. Mechanisms of action of probiotics: recent advances. Inflamm Bowel Dis 2009; 15:300-310.

13. Reid G, Younes JA, Van der Mei HC, Gloor GB, Knight R, Busscher HJ. Microbiota restoration: natural and supplemented recovery of human microbial communities. Nat Rev Microbiol 2011;9:27-38.

14. Cerf-Bensussan N, Gaboriau-Routhiau V. The immune system and the gut microbiota: friends or foes? Nat Rev Immunol 2010;10:735744.

15. Quigley EM. Bacterial flora in irritable bowel syndrome: role in pathophysiology, implications for management. J Dig Dis 2007;8:2-7.

16. Salonen A, de Vos WM, Palva A. Gastrointestinal microbiota in irritable bowel syndrome: present state and perspectives. Microbiology 2010;156(Pt 11):3205-3215.

17. Quigley EM, Flourie B. Probiotics and irritable bowel syndrome: a rationale for their use and an assessment of the evidence to date. Neurogastroenterol Motil 2007;19:166-172.

18. Ringel Y, Carroll IM. Alterations in the intestinal microbiota and functional bowel symptoms. Gastrointest Endosc Clin N Am 2009; 19:141-150, vii.

19. Spiller R, Campbell E. Post-infectious irritable bowel syndrome. Curr Opin Gastroenterol 2006;22:13-17.

20. Rhodes DY, Wallace M. Post-infectious irritable bowel syndrome. Curr Gastroenterol Rep 2006;8:327-332.

21. Thomas CM, Versalovic J. Probiotics-host communication: Modulation of signaling pathways in the intestine. Gut Microbes 2010;1: 148-163.

22. Rolfe VE, Fortun PJ, Hawkey CJ, Bath-Hextall F. Probiotics for maintenance of remission in Crohn's disease. Cochrane Database Syst Rev 2006;18:CD004826.

23. Mohamadzadeh M, Pfeiler EA, Brown JB, et al. Regulation of induced colonic inflammation by Lactobacillus acidophilus deficient in lipoteichoic acid. Proc Natl Acad Sci U S A 2011;108(suppl 1):4623-4630.

24. Artis D. Epithelial-cell recognition of ommensal bacteria and maintenance of immune homeostasis in the gut. Nat Rev Immunol 2008;8:411-420.

25. Hill DA, Artis D. Intestinal bacteria and the regulation of immune cell homeostasis. Annu Rev Immunol 2010;28:623-667.

26. Guarner F, Malagelada JR. Gut flora in health and disease. Lancet 2003;361:512-519.

27. Macpherson AJ, Geuking MB, McCoy KD. Immune responses that adapt the intestinal mucosa to commensal intestinal bacteria. Immunology 2005;115:153-162.

28. Kapsenberg ML. Dendritic-cell control of pathogen-driven T-cell polarization. Nat Rev Immunol 2003;3:984-993.

29. Pimentel M, Lembo A, Chey WD, et al. Rifaximin therapy for patients with irritable bowel syndrome without constipation. N Engl J Med 2011;364:22-32.

30. Barbara G, Stanghellini V, Cremon C, De Giorgio R, Corinaldesi R. Almost all irritable bowel syndromes are post-infectious and respond to probiotics: controversial issues. Dig Dis 2007;25:245-248.

31. McKendrick MW, Read NW. Irritable bowel syndrome--post salmonella infection. J Infect 1994;29:1-3.

32. Thornley JP, Jenkins D, Neal K, Wright T, Brough J, Spiller RC. Relationship of Campylobacter toxigenicity in vitro to the development of postinfectious irritable bowel syndrome. J Infect Dis 2001;184: 606-609.

33. Ji S, Park H, Lee D, Song YK, Choi JP, Lee SI. Post-infectious irritable bowel syndrome in patients with Shigella infection. J Gastroenterol Hepatol 2005;20:381-386.

34. Spiller RC. Is IBS caused by infectious diarrhea? Nat Clin Pract Gastroenterol Hepatol 2007;4:642-643.

35. Gwee KA. Post-infectious irritable bowel syndrome, an inflammation-immunological model with relevance for other IBS and functional dyspepsia. J Neurogastroenterol Motil 2010;16:30-34.

36. Marshall JK, Thabane M, Garg AX, Clark WF, Salvadori M, Collins SM. Incidence and epidemiology of irritable bowel syndrome after a large waterborne outbreak of bacterial dysentery. Gastroenterology 2006;131:445-450.

37. Rana SV, Sinha SK, Sikander A, Bhasin DK, Singh K. Study of small intestinal bacterial overgrowth in North Indian patients with irritable bowel syndrome: a case control study. Trop Gastroenterol 2008;29: $23-25$. 
38. Gwee KA, Collins SM, Read NW, et al. Increased rectal mucosal expression of interleukin 1 beta in recently acquired post-infectious irritable bowel syndrome. Gut 2003;52:523-526.

39. Lee KJ, Kim YB, Kim JH, Kwon HC, Kim DK, Cho SW. The alteration of enterochromaffin cell, mast cell, and lamina propria T lymphocyte numbers in irritable bowel syndrome and its relationship with psychological factors. J Gastroenterol Hepatol 2008;23:16891694.

40. Lin HC. Small intestinal bacterial overgrowth: a framework for understanding irritable bowel syndrome. JAMA 2004;292:852-858.

41. Lee HR, Pimentel M. Bacteria and irritable bowel syndrome: the evidence for small intestinal bacterial overgrowth. Curr Gastroenterol Rep 2006;8:305-311.

42. Pimentel M. Review of rifaximin as treatment for SIBO and IBS. Expert Opin Investig Drugs 2009;18:349-358.

43. Pimentel M, Chatterjee S, Chow EJ, Park S, Kong Y. Neomycin improves constipation-predominant irritable bowel syndrome in a fashion that is dependent on the presence of methane gas: subanalysis of a double-blind randomized controlled study. Dig Dis Sci 2006;51: 1297-1301.

44. Høverstad T, Carlstedt-Duke B, Lingaas E, et al. Influence of oral intake of seven different antibiotics on faecal short-chain fatty acid excretion in healthy subjects. Scand J Gastroenterol 1986;21:997-1003.

45. Tana C, Umesaki Y, Imaoka A, Handa T, Kanazawa M, Fukudo S. Altered profiles of intestinal microbiota and organic acids may be the origin of symptoms in irritable bowel syndrome. Neurogastroenterol Motil 2010;22:512-519, e114-e115.

46. Balsari A, Ceccarelli A, Dubini F, Fesce E, Poli G. The fecal microbial population in the irritable bowel syndrome. Microbiologica 1982;5:185-194.

47. Si JM, Yu YC, Fan YJ, Chen SJ. Intestinal microecology and quality of life in irritable bowel syndrome patients. World J Gastroenterol 2004;10:1802-1805.

48. Mättö J, Maunuksela L, Kajander K, et al. Composition and temporal stability of gastrointestinal microbiota in irritable bowel syndrome - a longitudinal study in IBS and control subjects. FEMS Immunol Med Microbiol 2005;43:213-222.

49. Malinen E, Krogius-Kurikka L, Lyra A, et al. Association of symptoms with gastrointestinal microbiota in irritable bowel syndrome. World J Gastroenterol 2010;16:4532-4540.

50. Kerckhoffs APM, Samsom M, van der Rest ME, et al. Lower Bifidobacteria counts in both duodenal mucosa-associated and fecal microbiota in irritable bowel syndrome patients. World J Gastroenterol 2009;15:2887-2892.

51. Swidsinski A, Weber J, Loening-Baucke V, Hale LP, Lochs H. Spatial organization and composition of the mucosal flora in patients with inflammatory bowel disease. J Clin Microbiol 2005;43:33803389.

52. Malinen E, Rinttila T, Kajander K, et al. Analysis of the fecal microbiota of irritable bowel syndrome patients and healthy controls with real-time PCR. Am J Gastroenterol 2005;100:373-382.

53. Noor SO, Ridgway K, Scovell L, et al. Ulcerative colitis and irritable bowel patients exhibit distinct abnormalities of the gut microbiota. BMC Gastroenterol 2010;10:134.

54. Krogius-Kurikka L, Lyra A, Malinen E, et al. Microbial community analysis reveals high level phylogenetic alterations in the overall gas- trointestinal microbiota of diarrhoea-predominant irritable bowel syndrome sufferers. BMC Gastroenterol 2009;9:95.

55. O'Sullivan M, Clayton N, Breslin NP, et al. Increased mast cells in the irritable bowel syndrome. Neurogastroenterol Motil 2000;12: 449-457.

56. Barbara G, Stanghellini V, De Giorgio R, et al. Activated mast cells in proximity to colonic nerves correlate with abdominal pain in irritable bowel syndrome. Gastroenterology 2004;126:693-702.

57. Gribar SC, Anand RJ, Sodhi CP, Hackam DJ. The role of epithelial toll-like receptor signaling in the pathogenesis of intestinal inflammation. J Leukoc Biol 2008;83:493-498.

58. Brint EK, Macsharry J, Fanning A, Shanahan F, Quigley EM. Differential expression of toll-like receptors in patients with irritable bowel syndrome. Am J Gastroenterol 2011;106:329-336.

59. Schoepfer AM, Schaffer T, Seibold-Schmid B, Müller S, Seibold F. Antibodies to flagellin indicate reactivity to bacterial antigens in IBS patients. Neurogastroenterol Motil 2008;20:1110-1118.

60. Voss E, Wehkamp J, Wehkamp K, Stange EF, Schröder JM, Harder J. NOD2/CARD15 mediates induction of the antimicrobial peptide human beta-defensin-2. J Biol Chem 2006;281:2005-2011.

61. Langhorst J, Junge A, Rueffer A, et al. Elevated human beta-defensin-2 levels indicate an activation of the innate immune system in patients with irritable bowel syndrome. Am J Gastroenterol 2009; 104:404-410.

62. Ohman L, Isaksson S, Lindmark AC, et al. T-cell activation in patients with irritable bowel syndrome. Am J Gastroenterol 2009;104: 1205-1212.

63. Aerssens J, Camilleri M, Talloen W, et al. Alterations in mucosal immunity identified in the colon of patients with irritable bowel syndrome. Clin Gastroenterol Hepatol 2008;6:194-205.

64. Forsythe P, Bienenstock J. Immunomodulation by commensal and probiotic bacteria. Immunol Invest 2010;39:429-448.

65. Nobaek S, Johansson ML, Molin G, Ahrné S, Jeppsson B. Alteration of intestinal microflora is associated with reduction in abdominal bloating and pain in patients with irritable bowel syndrome. Am J Gastroenterol 2000;95:1231-1238.

66. Marshall JK, Thabane M, Garg AX, Clark W, Meddings J, Collins SM. Intestinal permeability in patients with irritable bowel syndrome after a waterborne outbreak of acute gastroenteritis in Walkerton, Ontario. Aliment Pharmacol Ther 2004;20:1317-1322.

67. Spiller RC, Jenkins D, Thornley JP, et al. Increased rectal mucosal enteroendocrine cells, $\mathrm{T}$ lymphocytes, and increased gut permeability following acute Campylobacter enteritis and in post-dysenteric irritable bowel syndrome. Gut 2000;47:804-811.

68. Hooper LV, Wong MH, Thelin A, Hansson L, Falk PG, Gordon JI. Molecular analysis of commensal host-microbial relationships in the intestine. Science 2001;291:881-884.

69. Zeng J, Li YQ, Zuo XL, Zhen YB, Yang J, Liu CH. Clinical trial: effect of active lactic acid bacteria on mucosal barrier function in patients with diarrhoea-predominant irritable bowel syndrome. Aliment Pharmacol Ther 2008;28:994-1002.

70. Bouma G, Strober W. The immunological and genetic basis of inflammatory bowel disease. Nat Rev Immunol 2003;3:521-533.

71. Willing BP, Gill N, Finlay BB. The role of the immune system in regulating the microbiota. Gut Microbes 2010;1:213-223.

72. Pagnini C, Saeed R, Bamias G, Arseneau KO, Pizarro TT, 
Cominelli F. Probiotics promote gut health through stimulation of epithelial innate immunity. Proc Natl Acad Sci U S A 2010;107: 454-459.

73. Liu Y, Fatheree NY, Mangalat N, Rhoads JM. Human-derived probiotic Lactobacillus reuteri strains differentially reduce intestinal inflammation. Am J Physiol Gastrointest Liver Physiol 2010;299: G1087-G1096.

74. O'Mahony L, McCarthy J, Kelly P, et al. Lactobacillus and Bifidobacterium in irritable bowel syndrome: symptom responses and relationship to cytokine profiles. Gastroenterology 2005;128:541-551.

75. Liebregts T, Adam B, Bredack C, et al. Immune activation in patients with irritable bowel syndrome. Gastroenterology 2007;132: 913-920.

76. Ohman L, Lindmark AC, Isaksson S, et al. B-cell activation in patients with irritable bowel syndrome (IBS). Neurogastroenterol Motil 2009;21:644-650, e27.

77. Amaral FA, Sachs D, Costa VV, et al. Commensal microbiota is fundamental for the development of inflammatory pain. Proc Natl Acad Sci U S A 2008;105:2193-2197.

78. Verdú EF, Bercík P, Bergonzelli GE, et al. Lactobacillus paracasei normalizes muscle hypercontractility in a murine model of postinfective gut dysfunction. Gastroenterology 2004;127:826-837.

79. Wang B, Mao YK, Diorio C, et al. Lactobacillus reuteri ingestion and $\mathrm{IK}(\mathrm{Ca})$ channel blockade have similar effects on rat colon motility and myenteric neurones. Neurogastroenterol Motil 2010;22: 98-107, e33.

80. Rousseaux C, Thuru X, Gelot A, et al. Lactobacillus acidophilus modulates intestinal pain and induces opioid and cannabinoid receptors. Nat Med 2007;13:35-37.

81. Verdú EF, Bercik P, Verma-Gandhu M, et al. Specific probiotic therapy attenuates antibiotic induced visceral hypersensitivity in mice. Gut 2006;55:182-190.

82. Kunze WA, Mao YK, Wang B, et al. Lactobacillus reuteri enhances excitability of colonic AH neurons by inhibiting calcium-dependent potassium channel opening. J Cell Mol Med 2009;13:2261-2270.

83. Ma X, Mao YK, Wang B, Huizinga JD, Bienenstock J, Kunze W. Lactobacillus reuteri ingestion prevents hyperexcitability of colonic DRG neurons induced by noxious stimuli. Am J Physiol Gastrointest Liver Physiol 2009;296:G868-G875.

84. McKernan DP, Fitzgerald P, Dinan TG, Cryan JF. The probiotic Bifidobacterium infantis 35624 displays visceral antinociceptive effects in the rat. Neurogastroenterol Motil 2010;22:1029-1035, e268.

85. Bär F, Von Koschitzky H, Roblick U, et al. Cell-free supernatants of Escherichia coli Nissle 1917 modulate human colonic motility: evidence from an in vitro organ bath study. Neurogastroenterol Motil 2009;21:559-566, e16-e17.

86. Guarino MP, Altomare A, Stasi E, et al. Effect of acute mucosal exposure to Lactobacillus rhamnosus GG on human colonic smooth muscle cells. J Clin Gastroenterol 2008;42(suppl 3 Pt 2):S185-S190.

87. Quigley EM. Probiotics in functional gastrointestinal disorders: what are the facts? Curr Opin Pharmacol 2008;8:704-708.

88. Brenner DM, Moeller M, Chey WD, Schoenfeld PS. The utility of probiotics in the treatment of irritable bowel syndrome: a systematic review. Am J Gastroenterol 2009;104:1033-1049.

89. Moayyedi P, Ford AC, Talley NJ, et al. The efficacy of probiotics in the treatment of irritable bowel syndrome: a systematic review. Gut 2010;59:325-332.
90. McFarland LV, Dublin S. Meta-analysis of probiotics for the treatment of irritable bowel syndrome. World J Gastroenterol 2008;14: 2650-2661.

91. Hoveyda N, Heneghan C, Mahtani KR, Perera R, Roberts N, Glasziou P. A systematic review and meta-analysis: probiotics in the treatment of irritable bowel syndrome. BMC Gastroenterol 2009;9:15.

92. Parkes GC, Sanderson JD, Whelan K. Treating irritable bowel syndrome with probiotics: the evidence. Proc Nutr Soc 2010;69:187-194.

93. Chang JY, Talley NJ. Current and emerging therapies in irritable bowel syndrome: from pathophysiology to treatment. Trends Pharmacol Sci 2010;31:326-334.

94. Enck P, Zimmermann K, Menke G, Müller-Lissner S, Martens U, Klosterhalfen S. A mixture of Escherichia coli (DSM 17252) and Enterococcus faecalis (DSM 16440) for treatment of the irritable bowel syndrome - a randomized controlled trial with primary care physicians. Neurogastroenterol Motil 2008;20:1103-1109.

95. Whorwell PJ, Altringer L, Morel J, et al. Efficacy of an encapsulated probiotic Bifidobacterium infantis 35624 in women with irritable bowel syndrome. Am J Gastroenterol 2006;101:1581-1590.

96. Guyonnet D, Chassany O, Ducrotte P, et al. Effect of a fermented milk containing Bifidobacterium animalis DN-173 010 on the health-related quality of life and symptoms in irritable bowel syndrome in adults in primary care: a multicentre, randomized, double-blind, controlled trial. Aliment Pharmacol Ther 2007;26:475486.

97. Enck P, Zimmermann K, Menke G, Klosterhalfen S. Randomized controlled treatment trial of irritable bowel syndrome with a probiotic E. coli preparation (DSM17252) compared to placebo. Z Gastroenterol 2009;47:209-214.

98. Shin HY, Song YS, Kim HM, Shin TY. Inhibitory effect of inflammatory cytokines production from activated mast cells by Gamisopoonghwanghyul-tang. Immunopharmacol Immunotoxicol 2004;26:587-596.

99. Niv E, Naftali T, Hallak R, Vaisman N. The efficacy of Lactobacillus reuteri ATCC 55730 in the treatment of patients with irritable bowel syndrome - a double blind, placebo-controlled, randomized study. Clin Nutr 2005;24:925-931.

100. Bausserman M, Michail S. The use of Lactobacillus GG in irritable bowel syndrome in children: a double-blind randomized control trial. J Pediatr 2005;147:197-201.

101. Niedzielin K, Kordecki H, Birkenfeld B. A controlled, double-blind, randomized study on the efficacy of Lactobacillus plantarum $299 \mathrm{~V}$ in patients with irritable bowel syndrome. Eur J Gastroenterol Hepatol 2001;13:1143-1147.

102. Sen S, Mullan MM, Parker TJ, Woolner JT, Tarry SA, Hunter JO. Effect of Lactobacillus plantarum $299 \mathrm{v}$ on colonic fermentation and symptoms of irritable bowel syndrome. Dig Dis Sci 2002;47: 2615-2620.

103. Kajander K, Hatakka K, Poussa T, Färkkilä M, Korpela R. A probiotic mixture alleviates symptoms in irritable bowel syndrome patients: a controlled 6-month intervention. Aliment Pharmacol Ther 2005;22:387-394.

104. Kajander K, Myllyluoma E, Rajilić-Stojanović M, et al. Clinical trial: multispecies probiotic supplementation alleviates the symptoms of irritable bowel syndrome and stabilizes intestinal microbiota. Aliment Pharmacol Ther 2008;27:48-57. 
105. Kim HJ, Camilleri M, McKinzie S, et al. A randomized controlled trial of a probiotic, VSL\#3, on gut transit and symptoms in diarrhoea-predominant irritable bowel syndrome. Aliment Pharmacol Ther 2003;17:895-904.

106. Kim HJ, Vazquez Roque MI, Camilleri M, et al. A randomized controlled trial of a probiotic combination VSL\# 3 and placebo in irritable bowel syndrome with bloating. Neurogastroenterol Motil 2005;17:687-696.

107. Hong KS, Kang HW, Im JP, et al. Effect of probiotics on symptoms in Korean adults with irritable bowel syndrome. Gut Liver 2009;3:101-107.

108. Sinn DH, Song JH, Kim HJ, et al. Therapeutic effect of Lactobacillus acidophilus-SDC 2012, 2013 in patients with irritable bowel syndrome. Dig Dis Sci 2008;53:2714-2718.

109. Gawrońska A, Dziechciarz P, Horvath A, Szajewska H. A random- ized double-blind placebo-controlled trial of Lactobacillus GG for abdominal pain disorders in children. Aliment Pharmacol Ther 2007;25:177-184.

110. Williams EA, Stimpson J, Wang D, et al. Clinical trial: a multistrain probiotic preparation significantly reduces symptoms of irritable bowel syndrome in a double-blind placebo-controlled study. Aliment Pharmacol Ther 2009;29:97-103.

111. Tsuchiya J, Barreto R, Okura R, Kawakita S, Fesce E, Marotta F. Single-blind follow-up study on the effectiveness of a symbiotic preparation in irritable bowel syndrome. Chin J Dig Dis 2004; 5:169-174.

112. Drouault-Holowacz S, Bieuvelet S, Burckel A, Cazaubiel M, Dray $\mathrm{X}$, Marteau P. A double blind randomized controlled trial of a probiotic combination in 100 patients with irritable bowel syndrome. Gastroenterol Clin Biol 2008;32:147-152. 